\title{
Water Contact Patterns and Urinary Schistosomiasis Transmission among School Children in Endemic Area of Wudil, Kano, Nigeria
}

\author{
${ }^{\mathrm{a}}$ Ahmad", M. M., ${ }^{\mathrm{a}}$ Getso, B. U. and ${ }^{\mathrm{b}}$ Ahmad, U. A. \\ ${ }^{a}$ Department of Biology,Kano University of Science and Technology, Wudil \\ ${ }^{b}$ Department of Biology, Jigawa State University, Kafin- Hausa
}

\begin{abstract}
The aim of this study was to ascertain the role and relative importance of water Contact activities in the transmission of Urinary Schistosomiasis during the study period.Different water contact activities were observed and recorded among the subjects in the study area. While on the other hand, 200 Urine samples were collected and examined for the presence of blood in the urine using strip-reagent method as confirmation to Schistosomiasis infection.As well, a sedimentation technique was employed to detect the presence or otherwise of Schistosome ova in the urine samples. Out of these 200 urine samples, 25\% (50) were found to be positive with S. haematobium. Male children recorded the highest cases of $88 \%$ (44), while female has only $12 \%$ (6) of the total samples observed. Children between the ages of 11-14 years have the peak prevalence of 78\% (39), while those within 7-10 years of age have 22\% (11) respectively.Children who engaged in swimming in water has the highest rates of 68\% (34), followed by washing 12\% (6) and the least contact patterns was farming with only $8 \%$ (4).This result was by far less than what were obtained in the previous studies in some areas and may not be unconnected with the level of awareness by these school children and their limited contact with the water.

Key words: Water Contact, Prevalence, Urinary Schistosomiasis, Children, Transmission
\end{abstract}

\section{Introduction}

Urinary Schistosomiasis is a human disease condition, which is caused by infection of the trematodeSchistosoma haematobium. The parasite is found in the venous plexus draining the urinary bladder of humans (WHO, 1985). During infection, the parasites deposit terminal spine eggs which clog the venous plexus, impeding blood flow. This bursts the veins, allowing blood and eggs to enter the urinary bladder, resulting in the characteristic symptom of blood in urine or haematuria (WHO, 1985). In sub-Saharan Africa alone it is estimated that 70 million individuals experience heamaturia, 32 million with difficulty in urinating (dysuria), 18 million with bladder-wall pathology, and 10million with major hydronephrosis from infection caused by Schistosoma haematobium. Mortality rate due to nonfunctioning kidney (from S. haematobium) and haematemesishas been put at 150,000 per year (Van Der Warf, et. al., 2003). The above figure simply that urinary Schistosomiasis is an important public health problem in sub-Saharan Africa and second to malaria in morbidity (WHO, 1993).Urinary Schistosomiasis is endemic in Nigeria in general(WHO, 1985). Although there is no current estimate of the disease in the country, past estimates have put the infection at about 25 million people and 101 million at risk of infection respectively (Chitsulo, et. al., 2000).

The case of Schistosomiasis (snail-fever or bilharziasis) as observed in this study on the community having regular contact with the infected water bodies; perfectly fits into the description of the disease by the Harvard school of Health, Harvard University "as a disease of the poor that typically afflicts rural dwellers, especially school-aged children, women and fishermen groups who lack access to safe water and sanitation and whose daily activities bring them into direct contact with infected water-sources (Jordan, 1975; Ogbeide, et al., 2004). Of equal importance to the transmission of water-borne diseases (i.e. Schistosomiasis), is the nature of human water contact activities. Fishing, swimming, washing clothes, bathing and playing in water have been indicated as the most important water contact activities which play major role in the prevalence and transmission of this disease (Tayoet al., 1980; Bassey, 1988 and Alozie, et al., 2004). Global statistics for mid2003 suggest that almost 800 million individuals were at risk of Schistosomiasis, 207 million were infected, 120 million suffered from clinical disease and 20 million exhibited severe morbidity (Chitsulo et al., 2000; Steinmann et al., 2006). An estimated $97 \%$ of all infected people are concentrated in Africa, which is partially explained by the social-ecological context detailed above, weak or non-existing health systems, poverty and general neglect (Hotez and Fenwick, 2009; Stothardet al., 2009a; Utzingeret al., 2009).

Development of water reservoirs and their close proximity to most communities was emphasized as an important factor enhancing water-contact activities and thereby increase in Schistosomiasis transmission (Bassey, 1988; Mu'azu 2008; Ofozie, 1995; Talla, et al., 1990; Jeffrey, et al., 2004; Scott, et al., 2003, Ofozie, 2002). Records of increased prevalence of Schistosomiasis in areas brought under irrigation, especially where 
basin irrigation(by the flooding water), is displaced with perennial irrigation in several parts of Africa have been shown by Khalil,(1990),Diaw, et al.,(1991), N'Goran, et al.,(1997),Simonson, et al.,(1990), Okpala, et al.,(2004).

Various forms of water contact activities such as swimming, playing, fishing irrigation, washing clothes and bathing has been found to enhance the transmission of this disease. Such activities were reported to be responsible for the transmission of the disease at RuwanSanyi dam site atMalumfashi in Northern Nigeria. In this area, boy of less than 21 years of age were found to account for more than $79 \%$ of the infection rate. Also, $67.7 \%$ prevalence rate was reported in Kura, $73.7 \%$ and $55 \%$ in Kadawa and GarunBabba all in Kura local government area of Kano State Northern Nigeria (Bichi, et. al. 2003). Also many such cases were reported in areas with close proximity with contaminated waters among this age group in some parts of Kano state (Mu'azu, 2008, Bassey, 1988,Ekpo, et. al., 2010, Betterton et. al., 1988).

\section{Materials and Methods}

This study was carried out at Wudil town, in Wudil local government area of Kano state in northern Nigeria extending an area between latitude $11^{\circ} 48^{\prime} \mathrm{N}$ and Longitude $8^{\circ} 50^{\prime} \mathrm{E}$. The area has two distinct seasons; Dry and rainy seasons. The dry season begins from late October to May with a spell of harmattan period from November to January and sometimes to early February. While the rainy season is usually short and commences in late May to September and in some case to early October.

\section{Data collection}

A total of 200 school children were randomly selected and enrolled for this study and standard questionnaire was distributed to children between the ages of 7-10 and 11-14 years at Wudil special primary schoolwho were assumed to be frequently visiting Wudil River for one form of water contact activity or another. They comprise of 146 males and 54 females pupils. The questionnaire was to ascertain among other, the age, sex, type of water contact activity and frequency, awareness of Schistosomiasis and its mode of transmission etc. After responding to the questionnaire, a clean urine bottle was given to each of these respondents and asked to produce their urine. Collection was done between the hours of 10am. - 2p.m.which corresponding to circadian rhythm and is assume to be the peak period for eggs in urine (Udonsi, 1990; Mu'azu, 2008' WHO, 1991).

\section{Samples analysis}

Sample collected was analysed using two methods;First indirect technique which involved visual observation of gross macro haematuria in the urine. Secondly a reagent strip soaked in a reactive agent (Comb9) was used to observe the presence of micro-haematuria in the urine samples collected. This strip was dipped in the sample and waited for as little as lessthan a minute and then removed, the band formed compared with the calorimetric scale(WHO, 1993; Lwamboet al., 1999)

\section{Parasitological analysis of collected samples}

$10 \mathrm{ml}$ of the urine sample was centrifuged at $5000 \mathrm{rpm}$ for 5 minutes. The supernatant was discarded to leave sediment which was transferred to the Centre of a clean grease-free glass slide to which was added a cover slip. This was mounted on a light microscope and examined at $\times 40$ objective to identify for the presence ofSchistosoma haematobium ova which is characterized with a terminal spine. The eggs were counted and recorded as eggs/10 $\mathrm{ml}$ of urine.

\section{Data analysis}

The recorded data were analysed based on simple percentage using contingency table to determine the rates of infection among the different sexes and age groups as well as the relationship between all the water contact activities and Schistosomiasis infection among the subjects.

\section{Results}

Out of 200 urine samples collected and examined; 146 (78\%) were male pupils, while 54 (27\%) were female pupils. Out of these figures $50(25 \%)$ were found to be positive for S. haematobium, while 150 (75\%) were negative. Male pupils accounted for $44(88 \%)$ and female $6(12 \%)$ for the recorded positive cases respectively (Table I).

Also, in term of age group, 99 (49.5\%) were 7-10 years age group, while $102(51 \%)$ were 11-14 years of age. Out of these $11(22 \%)$ were positiveand 88 (58.67\%) were negative among 7-10 years of age, while 39 $(78 \%)$ were positive and $62(41.33 \%)$ were negative among $11-14$ years age group (Table II).

Infection in relation to different patterns of water contact activities was higher among pupils who were engaged in swimming in water with $34(68 \%)$, farming/ irrigation activities has $4(8 \%)$, washing clothes was 
having $6(12 \%)$ and those who did not participated in any form of water contact activities had $6(12 \%)$ respectively (Table III).

\section{Discussion}

The prevalence and distribution of Schistosomiasis depend upon a number of important factors which include among others; availability of permanence contaminated water surfaces that harboured the intermediate snails host, ecological factors such as temperature and rainfall and as well as various socio-economic activities that resulted in various forms of water contact activities.. The children in and around the research area were habitually seen swimming in any available water collection such as pond, dam and rivers. They visited these waters freely to fetch water, wash their clothes, swim and sometimes agricultural activity, this could be strongly related to the higher prevalence rate among this age group in all areas covered by such a researches (Bassey, 1988).

From the result recorded in this study, 50 (25\%) out of 200 urine samples were found to be positive for urinary Schistosomiasis. This value is low compared to $49.9 \%$ in Farin- Gada village area of Plateau State by Akufangwe (1995), 67.9\% at Kadawa irrigation water Scheme by Bassey (1988), 52.2\% at Karfi by Yakasai (1997) and many more. This could have been due to increase in the awareness of the disease and its mode of transmission by the subjects. As well it may be due to reduced contact/ visit to the contaminated water.

However, prevalence rate with regard to age structure was highest among 11-14years of age group (78\%) and the least rate was among 7-10 years with (41.1\%) level. This agrees well with Pughet al., (1980a), Bassey (1988), Taylor and Makura (1984), Mu'azu (2008) and Bichiet al., (2003), who reported similar pattern of Schistosoma infection with teenagers having the highest peak level due to their active participation in various water contact activities in contaminated waters.

Prevalence level in relation to water contact activities showed that swimming had the highest rates $(68 \%)$, followed by washing (12\%), farming (8\%) and those non-participating subjects (8\%) respectively. Transmission rates were highly significant between different forms of water contact activities in relation to Schistosomiasis. As well as between male and female subjects (at $\mathrm{P}$ value both $5 \%$ and $1 \%$ level of significance). Hence it was concluded that this samples' results do not conform to the 1:1 ration. The difference in prevalence rate between male and female was due to socio-cultural behaviours in the study areas as reported by Taylor and Makura (1984). Also, Ukoli (1990) reported that human contacts with water arise for four major basic needs: occupation, recreation, domestic and socio- cultural activities.

Table I: Urinary Schistosomiasis transmission in relation to sex

\begin{tabular}{|c|c|c|c|}
\hline Sex & Number Examined & Number infected & Non- infected \\
\hline Male & $146(73 \%)$ & $44(88 \%)$ & $102(68 \%)$ \\
\hline Female & $54(27 \%)$ & $6(12 \%)$ & $48(32 \%)$ \\
\hline Total & $200(100 \%)$ & $50(27 \%)$ & $150(73 \%)$ \\
\hline
\end{tabular}

Table II: Urinary Schistosomiasis transmission in relation to age group

\begin{tabular}{llll}
\hline Age & Number Examined & Number infected & Non- infected \\
\hline & & & \\
$7-10$ years & 99 & $11(22 \%)$ & $88(58.67 \%)$ \\
$11-14$ years & 101 & $39(78 \%)$ & $62(41.33 \%)$ \\
\hline Total & $\mathbf{2 0 0}$ & $\mathbf{5 0}(\mathbf{2 7 \%})$ & $\mathbf{1 5 0}(\mathbf{7 3 \%})$ \\
\hline
\end{tabular}

Table III: Urinary Schistosomiasis transmission in relation to water contact patterns

\begin{tabular}{llll}
\hline Water contact patterns & Number Examined & Number infected & Non- infected \\
\hline & & & \\
Swimming & $52(26 \%)$ & $34(68 \%)$ & $18(12 \%)$ \\
Farming & $7(3.5 \%)$ & $4(8 \%)$ & $3(2 \%)$ \\
Washing & $9(4.5 \%)$ & $6(12 \%)$ & $3(2 \%)$ \\
Non-participant & $132(66 \%)$ & $6(12 \%)$ & $126(84 \%)$ \\
\hline Total & $\mathbf{2 0 0}$ & $\mathbf{5 0}(\mathbf{2 7 \%})$ & $\mathbf{1 5 0}(\mathbf{7 3 \%})$ \\
\hline
\end{tabular}

\section{References}

[1]. Alozie JI and Anosike J (2004): Prevalence of urinary Schistosomiasis in BendelLocal GovernmentArea ofAbia State, Nigeria. Animal Research International. (2004) 1(2): 77.

[2]. Bassey, SE (1988): The epidemiology of Schistosomiasis in the Kano Irrigation Project Area, Kano State.M.sc Theses, Bayero University, Kano, Nigeria.

[3]. Betterton C, Ndifon GT, Bassey SE, Tan RM and Oyeyi, T (1988): Schistosomiasis in Kano State, Nigeria. I. Human infections near dam sites and the distribution and habitat preferences of potentialsnail intermediate hosts, Annals of Tropical Medicine and,parasitology,77: 143-149. 
[4]. Bichi,, A. H., Taram, H. and Mukhtar, M. D. (2003): Incidence of S. haematobium and S. mansoni in Bichi General Hospital, Kano State.Africa Journal of Material and Science, Vol. 3, No. 2. 2003

[5]. Chitsulo L, Engels D, Montresor A, Savioli L (2000): The global status of Schistosomiasis and its control. Acta Trop, 2000, 77(1):41-51.

[6]. Diaw OT, Vassiliades G, Seye M and Sarr Y (1991): Epidemiologie de la bilharzioseintestinale aSchistosoma mansoni a RichardToll Delta du fleuve Senegal. Etude malacologigue, Bulletin De La SocieteDe PathologieExotique Et De SesFiliales, 84: 174-183.

[7]. Ekpo, U. F., Akintunde L., Akinola, S. O., Sammy, O. S. and Chiedu, F. M. (2010).Urinary Schistosomiasis among preschool childrenin a rural community near Abeokuta, Nigeria. Parasite and Vectors, 2010, 3:58

[8]. Hotez, P.J. and Fenwick, A.2009. Schistosomiasis in Africa: an emerging tragedy in our new global health decade. PLoSNegl. Trop. Dis. 3, e485.

[9]. Jeffrey B, Jeff T, Philip TL, Rodrigo C, and Helmut K (2004): Exposure to Schistosoma mansoni infection in rural areas in Brazil. Part III household aggregation of water-contact behaviour, Tropical Medicine and International Health; 9(3): 381-389.

[10]. Jordan, P (1975): Schistosomiasis: Epidemiology, clinical manifestation and control. In Man-made Lakes and Human Health, N. F. Stanley and M.D.Alper (eds.). Academy Press, London.pp. 35-49.

[11]. Khalil, M (1999): Journal of the Royal Egyptian Medical Association, 32: 820.

[12]. Lwambo, N.J.S., Siza, J. E., Brooker, S., Bundy D.A.P. and Guyyat, H.(1999).Pattern of concurrent infection with hookworm and Schistosomiasis in school children in Tanzania. Trans. Royal Society of Tropical Medicine and Hygiene, 93, 497-502.

[13]. Mu'azuAbdullahi (2008): A comprehensive Mapping of Urinary Schistosomiasis using Geographical Information Systems (GIS) in Kano State, Nigeria. PhD Thesis, B.U.K.

[14]. N'Goran GK, Diabete S, Utzinger J and Sillar B (1997): Changes in human Schistosomiasislevels after the construction of two large hydroelectric dams in central Cote de'voire,Bulletin World Health Organization.75 (6): 541-545.

[15]. Ofozie, IE (1995): A study of urinary Schistosomiasis in resettlement communities borderingOyan River Dam, Ogun State. Nigeria. PhD Thesis, ObafemiAwolowo University, Ile-IfeNigeria, 1992-1995.

[16]. Ofoezie, I. E.(2002). Human health and sustainable water resources development in Nigeria:

[17]. Schistosimiasis in artificial lakes.Natural Resources Forum.26, pp.150-160.

[18]. Ogbeide, H. E. and Uyigue, E.(2004). Access to safe drinking water and schistosomiasis in Nigeria: survey on Ipogun Community, Ondo State of Nigeria. Submitted to the Society for Water and Public Health Protection (SWAPHEP), http://swaphep.virtualactivism.net.

[19]. Okpala HO, Agwu E, Agba MI, Chimezie JR, Nwogu GO, and Ohihion AA (2004): A survey of the prevalence of Schistosomiasis among pupils in Apata andLaranto areas in Jos, Plateau State, Nigeria. Online Journal of Health and Allied Science,2004, 1: 1 .

[20]. Pugh RNH, Bell DR and Gilles HM (1980a): Malumfashi Endemic Diseases Research Project XV:The potential medical importance of Bilharziasis in Northern Nigeria: A suggested rapid, cheap and effective solution to control of Schistosoma haematobium infection. Ann. Trop. Med. Parasitol., 74: 577-613.

[21]. Scott JT, Daikhate M, Vereecken K, Fall A, Drop M, Ly A, De clercq D, de Vlas SJ, Berkvens D, Kestens L, and Gryseels B (2003): Human water contacts patterns In Schistosoma mansoni epidemic foci in northern Senegal change according to age, sex, and place of residence, but are not related to intensity of infection. Tropical Medicine and International Health;8(2): 100-108

[22]. Simonsen PE, Nega A and Furu P (1990): Intestinal Schistosomiasis among children in a Labour Village of Wonji Sugar Estate, Ethiopia, East African Medical Journal, 67: 532-538.

[23]. Steinmann, P. Keisar, J. Bos, R. Tanner,M. and Utzinger,J. (2006). Schistosomiasis and water resources development: Systematic review, meta-analysis and Estimates of people at risk. Lancet Infect Disease. 6:411-25.

[24]. Stothard, J.R., Chitsulo, L., Kristensen, T.K. and Utzinger, J.(2009). Control of Schistosomiasis in sub- Saharan Africa: progress made new opportunities and remaining challenges. Parasitology 136, 1665-1675.

[25]. Talla I, Kongs A, Verle P, Belot J, Sarr S and Coll AM (1990): Outbreak of Intestinal schistosomiasisin the Senegal River Basin, Annales De La SocieteBelge De Medecine Tropicale,70:173-180.

[26]. Tayo MA, Pugh RNH and Bradley K (1980): Malumfashi Endemic Diseases Research Project XI. Watercontact activities in the Schistosomiasisstudy area. Ann. Trop. Med. Parasitol. 79 (3): 347-354.

[27]. Udonsi, J. K.(1990).Human community ecology of Urinary Schistosomiasis in relation to snail vector bionomics in the Igwun River.Trop.Med. Parasitol., 41, 131-135.

[28]. Ukoli, F. M. A. (1990). Introduction to Parasitology in Tropical Africa, Vol. 4, Pp, 55-561.

[29]. Utzinger, J., Raso, G., Brooker, S., de Savigny, D., Tanner, M., Ornbjerg, N., Singer, B.H. and N'Goran, E.K. (2009). Schistosomiasis and neglected tropical diseases: towards integrated and sustainable control and a word of caution. Parasitology 136, 1859-1874.

[30]. Van der Werf MJ, De Vlas SJ, Brooker S, Looman CWN, Nagelkerke NJD, Habbema JDF, Engels D (2003): Quantification of clinical morbidity associated with Schistosome infection in sub-Saharan Africa. Acta Trop, 2003, 86:125-139.

[31]. World Health Organization(1985):The Control of Schistosomiasis WHO, Geneva;1985. Report of a WHO Expert Committee, Technical Report Series 728

[32]. World Health Organization (1991): Basic Laboratory Methods in Medical Parasitology. World Health Organization, Geneva.

[33]. World Health Organization (1993): Schistosomiasis: In: The Prescriber: Guidelines on the rational use of drugs in Basic Health Services, United Nation Children Emergency Fund (UNICEF), in Cooperation with La Reveu Prescriber (France). VI: 1-4.

[34]. World Health Organization(1993): The control of Schistosomiasis WHO Geneva;1993. Report of the WHO Expert Committee, Technical Report Series 830

[35]. World Health Organization (1993).Guidelines for the evaluation of soil transmitted helminthiasis and Schistosomiasis at community level, a guide for managers of control programme WHO/CTD/ISP/98.1.

[36]. Yakasai, M. U. (1991): Prevalence of Schistosoma haematobium infection in Karfi Area, Kura local government Kano State (Unpublished), B. Sc. Thesis, Department of Biology, Bayero University, Kano. 